\section{Basic comanittee and management skills for senior trainees in psychiatry}

DeAR SIR

The May issue of the Bulletin contained a notice of a British Postgraduate Medical Federation workshop on basic committee and management skills for senior trainees in psychiatry. Your brief announcement of the workshop did not do justice to it.

Although my undergraduate training in community medicine at Aberdeen and my postgraduate training in psychiatry at Edinburgh probably provided me with a better understanding of health service administration than many of my contemporaries, that knowledge needed extending and updating, particularly in view of the administrative changes which are currently taking place. I had not previously been trained in communication and management skills, and the workshop, in this respect, filled a crucial gap in my training as a psychiatrist.

The workshop had been carefully planned, it was skilfully administered, there was only one occasion when I nearly fell asleep, almost every component was very useful, no one sneaked out of sessions or left before the end, and it almost finished on time. These tributes are a reflection of the tutors' own command of the very skills they were teaching.

Although psychiatry is regarded as a 'cinderella specialty', our fairy godmothers have to be sought out and persuaded of our wish to go to the ball and so the skills taught by this workshop have a relevance outside clinical practice which is becoming more and more important. Indeed, they may soon be regarded as 'survival skills'.

I recommend this course to other senior trainees in psychiatry and suggest that it would also be of value to junior trainees and-dare I say it-to some consultant psychiatrists.

\section{Reviews}

Can Social Work Survive? by Colin Brewer and June Lait. Maurice Temple Smith. 1980. Pp. 235. £9.95.

The term 'social work' is liable to provoke an emotional response among psychiatrists. A variety of factors enter into this. It is a young profession and displays some of the features of a troubled adolescent. Uncertainty of identity, intense soul-searching, idealistic striving and utopian desires, defensive withdrawal and radical political views are all discernible. Whereas the medical profession can (with some justification) be perceived as the older generation, with conservative and authoritarian attitudes, sceptical and often irritated by the views expressed by the youngster.

Something of the exasperation engendered by this 'generation gap' is conveyed by the tone of this devil's advocate of a
As far as I know, with the exception of the course run by the Manchester Business School about which honorary senior registrars are not automatically notified, this is the only course of its kind. Such training ought to be more widely available and more actively encouraged by the College. If I was a nurse I would have been on my first management course at least ten years ago and I would have attended at least two more advanced courses already.

KeITH J. B. RIX

University of Manchester,

Manchester, M13 9PL.

[See also 'A Firmer Grounding' by Peter Hill and Helena Waters, July Bulletin, p. 123-Eds.]

\section{Patients with morbid grief or with obsessive- compulstive rituals}

\section{DEAR SIR}

Readers may be interested to know that our MRC team is currently trying to replicate our recent findings concerning the value of guided mourning in the management of morbid grief. We are also involved in further investigation of clomipramine and exposure treatment of obsessivecompulsive ritualizers (British Journal of Psychiatry, (1980), 136, 1-25). Patients referred with morbid grief or compulsive rituals can be assessed by us within two weeks, and if suitable can then be taken on immediately for treatment.

S. D. COHEN

W. MONTEIRO

I. M. MARKS

99 Denmark Hill

Maudsley Hospital

London, SE5 8AF

book. The authors point inter alia to the lack of a clear theoretical framework in social work, the absence of a sufficiently critical approach by social workers to their activities and effectiveness, the opaque jargon often employed, their preference for case-work (not as yet of proven value) rather than helping with practical matters, and indifferent record keeping. But criticism on each of these points can, it is fair to say, be levelled at psychiatry also.

The authors regret the establishment of bureaucratically top-heavy, expensive and somewhat isolated social services departments, the diffusion of responsibility in social work hierarchies and the diminished client involvement apparently inevitable on promotion. As regards mental illness, they feel that there is a strong case for abolishing the independent functioning of social work departments and bringing them back within the psychiatric services. 